\title{
Augmented Reality and Image-Guided Robotic Liver Surgery
}

\author{
Fabio Giannone ${ }^{1,2,3}$, Emanuele Felli ${ }^{1,2,3} \mathbb{D}$, Zineb Cherkaoui ${ }^{1,2}$, Pietro Mascagni ${ }^{3}$ and Patrick Pessaux $^{1,2,3, *}$ \\ 1 Department of Visceral and Digestive Surgery, University Hospital of Strasbourg, 1 Place de l'Hôpital, \\ 67100 Strasbourg, France; fabio.giannone@chru-strasbourg.fr (F.G.); e.felli@chu-tours.fr (E.F.); \\ zineb.cherkaoui@chru-strasbourg.fr (Z.C.) \\ 2 Institute of Viral and Liver Disease, Inserm U1110, University of Strasbourg, 1 Place de l'Hôpital, \\ 67100 Strasbourg, France \\ 3 University Hospital Institute (IHU), Institute of Image-Guided Surgery, University of Strasbourg, \\ 1 Place de l'Hôpital, 67100 Strasbourg, France; pietro.mascagni@ihu-strasbourg.eu \\ * Correspondence: patrick.pessaux@chru-strasbourg.fr; Tel.: +33-369-550-552
}

Citation: Giannone, F.; Felli, E.; Cherkaoui, Z.; Mascagni, P.; Pessaux, P. Augmented Reality and ImageGuided Robotic Liver Surgery. Cancers 2021, 13, 6268. https// doi.org/10.3390/cancers13246268

Academic Editors: Roland S. Croner, Andrew A. Gumbs and Mohammed Abu Hilal

Received: 5 November 2021

Accepted: 10 December 2021

Published: 14 December 2021

Publisher's Note: MDPI stays neutral with regard to jurisdictional claims in published maps and institutional affiliations.

Copyright: (C) 2021 by the authors Licensee MDPI, Basel, Switzerland. This article is an open access article distributed under the terms and conditions of the Creative Commons Attribution (CC BY) license (https:/ / creativecommons.org/licenses/by/ $4.0 /)$.
Simple Summary: Robotic surgery has gained much attention in liver resection for its potential to increase surgical dexterity in a minimally invasive scenario. Different series are reported in the literature with promising results, although strong evidence is lacking. In addition, the robotic system presents the advantage of creating a hybrid interface in which pre- and intra-operative imaging tools could be exploited alone or together in order to guide surgical resection. These technologies have been developed with the aim of increasing surgical safety and improving oncological results. However, some drawbacks are still present, and the literature lacks data given the relatively recent distribution of the robotic platform and of some of these technologies.

Abstract: Artificial intelligence makes surgical resection easier and safer, and, at the same time, can improve oncological results. The robotic system fits perfectly with these more or less diffused technologies, and it seems that this benefit is mutual. In liver surgery, robotic systems help surgeons to localize tumors and improve surgical results with well-defined preoperative planning or increased intraoperative detection. Furthermore, they can balance the absence of tactile feedback and help recognize intrahepatic biliary or vascular structures during parenchymal transection. Some of these systems are well known and are already widely diffused in open and laparoscopic hepatectomies, such as indocyanine green fluorescence or ultrasound-guided resections, whereas other tools, such as Augmented Reality, are far from being standardized because of the high complexity and elevated costs. In this paper, we review all the experiences in the literature on the use of artificial intelligence systems in robotic liver resections, describing all their practical applications and their weaknesses.

Keywords: robotic; liver surgery; augmented reality; image-guided surgery; artificial intelligence

\section{Introduction}

Since its presentation, the robotic platform has drawn much attention in liver resections for its possibility to combine the multiple advantages of laparoscopic surgery and the dexterity of an open approach [1,2]. Laparoscopy has widely demonstrated its benefits in terms of shortened recovery and reduced post-operative pain, morbidity, and blood loss, with similar results to open surgery in oncologic outcomes [3-7]. However, some issues are still present when considering technically challenging hepatectomies and most of these disadvantages are related to a limited maneuverability, the presence of rigid instruments, and a restricted field or the quality of vision [8]. Robotic technology is able to overcome some of these limitations and more series and meta-analysis are present in the literature, highlighting the well-known robotic advantages with comparable post-operative and oncological results [9-15]. Beyond the technical upgrades, one of the improvements of the DaVinci system is the possibility to create an interactive visual interface rather than a simple operative field in which, through some dedicated software, surgeons can be guided 
by preoperative and/or intraoperative imaging during parenchymal resection [16]. The robot must be considered as a means of putting between the surgeon and the patient a computer and its computing power. Related imaging technologies, such as Augmented Reality (AR), have been developed in order to assist the operator and limit the intrinsic drawbacks of a minimally invasive approach, such as the lack of a tactile feedback, which can hamper tumor detection or pedicle dissection.

In this article, we present an overview of the literature of AR technologies and other strategies of image-guided surgery in the robotic liver scenario. Specifically, we sought to describe all the current clinical and pre-clinical use as well as the future perspectives of imaging technologies used in combination with the robotic platform for treating benign and malign hepatic tumors.

\section{Augmented Reality}

Implementing technologies of robotic hepatic surgery through AR means overcoming the limitations widely described when performing liver resections through this approach. Despite the sense of depth achieved by the 3D visualization and the improved video resolution and magnification, the robotic system presents all the drawbacks of a minimally invasive view compared to an open hepatectomy. The absence of the tactile feedback and the unavailability of an ultrasonic dissector are undoubtedly the main issues found in this context. The importance of a tactile sensation is twofold in this kind of surgery. Firstly, from an oncological point of view, it helps locate the tumor and thus guide parenchymal transection. AR is effective in planning preoperatively the strategy through $3 \mathrm{D}$ rendering and, intraoperatively, targeting the lesion and resection margins (Figure 1) [17-21]. Buchs et al. [22], for example, overlaid the 3D preoperative images onto the endoscopic stream and added distance information in order to obtain a real-time guided transection. After projecting the tumor onto the liver surface and defining the margin width, a bar and a dartboard appeared on the screen to guide the tip of the instrument, with colors ranging from green to red to alert the operator if the distance to the tumor was respected or not. Ultrasound guidance or an intraoperative CT scan could be equally used, with the disadvantage of radiation, shifting the instruments constantly, or, occasionally, having difficulty localizing the nodules. In fact, AR has been described in open hepatectomies in the detection of vanishing metastasis, with the superimposition of lesions pre-existent to chemotherapy and undetectable at preoperative images or intraoperative US [23,24]. Secondly, the sense of touch aids the operator to orient him/herself in relation to some intra hepatic landmarks. Arteries, veins, and biliary structures, especially in the first-orders pedicles, present a thickened fibrotic sheath and the robotic "insensibility" can disorient surgeons during the dissection, with possible vascular injuries. Furthermore, lesions can be located in critical areas such as the hepatic confluence, and robotic dissection could thus be more complex [25]. AR-based intraoperative reconstructions and tracking systems may be used to map resection planes and show vascular structures during liver transection (Figure 1). Moreover, 3D planning can enable the identification of anatomical variants, as demonstrated in laparoscopic cholecystectomy [26]. These reconstructions could also represent a solution to the absence of some familiar devices in robotic liver surgery. Recently, a consensus statement suggested that in laparoscopic resections, a deep parenchymal transection must be performed by exposing intraparenchymal structures to avoid blind dissection and major vessel injury [2]. Nevertheless, the ultrasonic dissector and the articulated harmonic scalpel are missing in the robotic ecosystem, and, although no surgical technique has shown its superiority in parenchymal transection [27], some surgeons may be less comfortable without these devices. AR could overcome this gap and act as a support with a non-familiar technique, such as the clamp-crush. 


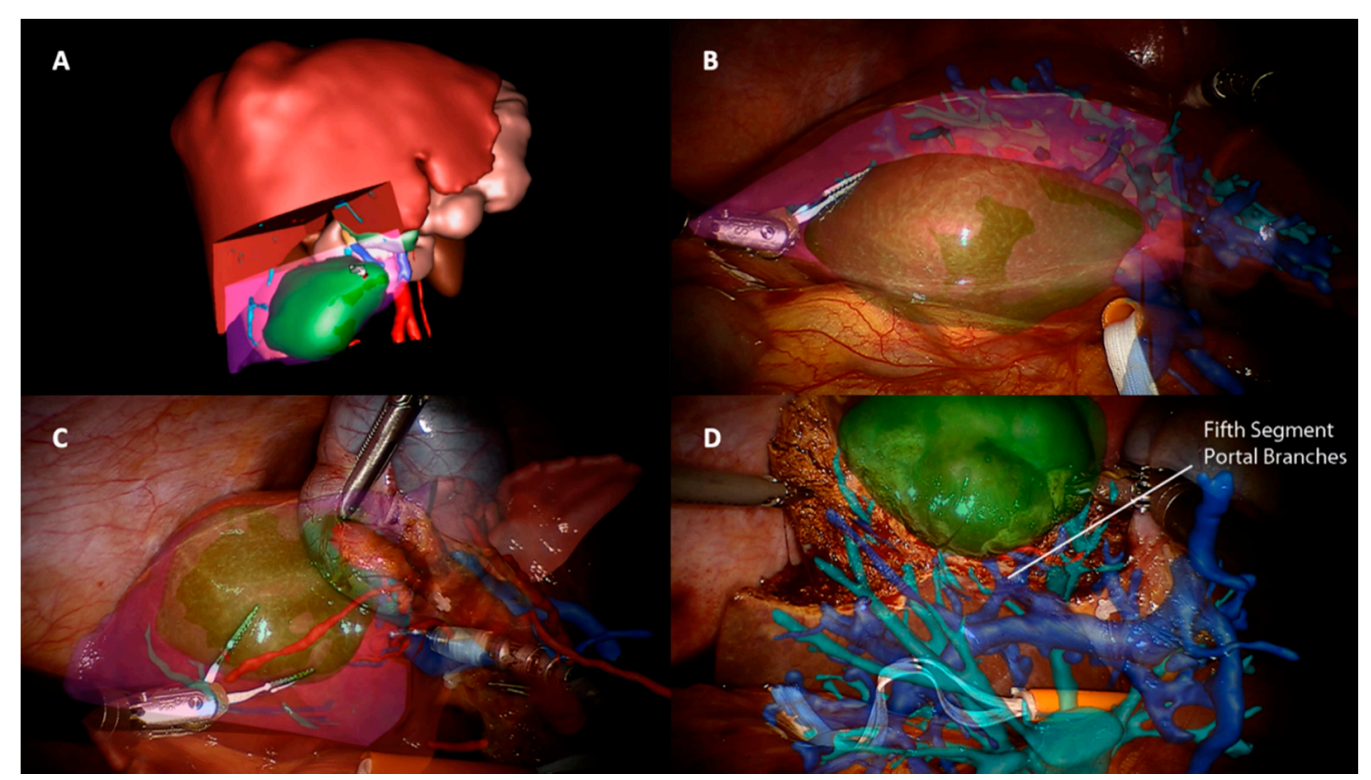

Figure 1. (A) Surgical preoperative planning through 3D reconstruction of an anatomical S5 segmentectomy. The tumor is colored in green and the theorical resection plane in red. (B-D) Intraoperative superimposition of planned resection area rendering. Vascular and biliary structures are projected during different phases of parenchymal transection, with the identification of the S5 vascular pedicle.

Another advantage of AR described for robotic liver resections is port placement (Figure 2) [28]. This phase is a key step in minimally invasive resections and even more in robotic surgery. Projecting a virtual image of the liver parenchyma on the skin surface in relation to some external landmarks allows targeting the lesion and liver structures at the beginning of the operation for camera placement and, after $\mathrm{CO}_{2}$ insufflation, for other ports. This results in an improved manageability of the operator, above all for posterior segment approach, which can lead to fewer operative times and lower intraoperative complications.



Figure 2. Projection of a virtual liver 3D reconstruction on the skin surface in relation to some external landmarks. The positioning of the optical port (left) is guided by the inferior border of the liver and the resection planned. After the first trocar is inserted, the "see-through" view will aid the operator to place other robotic ports (right).

\subsection{External Robot-Assisted Liver Ablation}

Radiofrequency and other types of transhepatic ablative procedures are usually proposed in selected cases to treat small hepatic lesions with comparable oncological safety to liver resections [29]. In this scenario, US guidance is normally adopted to localize the lesion and to verify the effect of the treatment. However, US lacks a 3D perception, and during the ablation, the procedure can create a scar or some artefacts that obscure the target, affecting treatment efficiency. Some authors proposed in preclinical studies the utilization of an AR interface to plan the procedure (Figure 3) and guide needle placement through a surgeon-robot cooperative system [30,31]. They concluded that the implementation of a 
3D interface combined with a human-computer interaction could improve the safety and accuracy of a percutaneous ablation, although results come from pre-clinical tests.

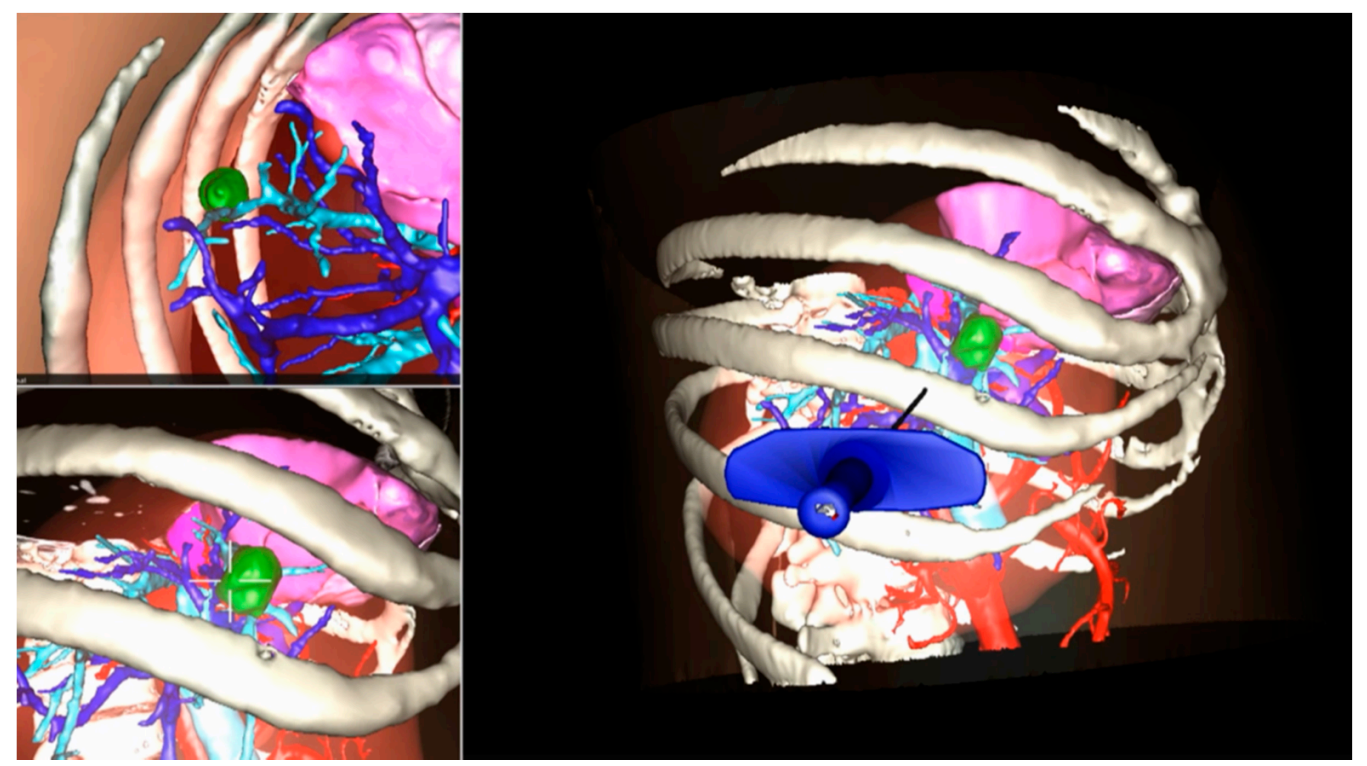

Figure 3. Use of Augmented Reality in planning needle placement during a percutaneous Radiofrequency liver ablation.

\subsection{Augmented Reality in Clinical Practice}

Potentialities of these technologies are theoretically limitless and could lead surgery to a simple, automatic, guided gesture. Nevertheless, we are still at the dawn of a new era and the literature lacks important series or prospective comparisons. To our knowledge, only two reports describe the use of AR in robotic liver resections [22,28]. The first report dates back to 2014 and was published by a Swiss group [22]. Two cirrhotic patients underwent an atypical resection for HCC and the authors concluded that the AR interface fit perfectly with the robotic environment and can represent a solution to difficulties in localizing hepatic lesions. Researchers at our center performed with success two robotic segmentectomies $\mathrm{V}$ (Figure 1) and one segmentectomy VI for both benign and malignant lesions, finding AR feasible but still under construction and with some drawbacks related to intraoperative registration in a "flexible" model, which limits the superimposition accuracy [28].

\section{Image-Guided Robotic Liver Surgery}

Although AR presents promising results, its application in ordinary life is under development because of the need for standardized algorithms, fully available technologies, and wide clinical data. At present, these drawbacks and the limited distribution of the robotic approach make this fascinating technology less attractive in clinical settings. Other imaging strategies are more frequently used by surgeons during robotic liver resections in order to improve lesion detection and evaluate intraparenchymal biliary and vascular structures. Before exploring these modalities, a special mention goes to TilePro (Intuitive Surgical Inc., Sunnyvale, CA, USA). This is a multi-input display software integrated into the robotic platform, which shows more video sources simultaneously on the same screen (Figure 2). By simply connecting an external source to the Da Vinci console, surgeons and other operating room assistants can easily switch from the operating field to other input such as Intraoperative Ultrasound (IOUS) or preoperative cross-sectional imaging and 3D reconstructions. Furthermore, some authors described the use of this tool during robotic abdominal resections in order to add an intra-operative endoscopic view, e.g., during colonoscopy in low anterior resection, gastroscopy in total gastrectomy, and even common bile duct exploration during left hepatectomy [32]. 
We next focus on the more common image-based tools and strategies used in combination with the robotic system to perform liver resections.

\subsection{Preoperative Imaging and $3 D$ Rendering}

A correct planification of surgical strategy is essential in liver surgery and it usually includes a 2D cross-sectional preoperative evaluation. However, complex liver intraparenchymal anatomy and anatomical variations can hinder a correct assessment made by a simple CT scan or MRI. Since its first description in 1998 [33], 3D liver reconstruction is nowadays performed more often during preoperative surgical planning. It consists of creating a 3D model starting from preoperative CT scan or MRI, which allows an easier identification of the stereoscopic relationships between the tumor and intrahepatic structures to calculate the hepatic volumes for the risk of post-operative liver failure and create resection plans to follow intraoperatively [34]. These features can be helpful in all types of resections, from anatomical hepatectomies to multiple metastasectomies in the context of a parenchymal sparing approach, or even in extended liver resections. Different retrospective studies found that hepatic surgery based on a preoperative 3D planning had several benefits in terms of operative time and peri-operative complications [18], resection margins [17], vascular resections [35], and oncological outcomes [36] compared to the traditional 2D evaluation. Several software for creating 3D models are on the market or even available as a free-beta, representing a valid solution for simulating a virtual resection and for intraoperative guidance. Despite such potential, liver rendering is still a multi-step and time-consuming technique with a not always optimal quality reconstruction and intraoperative adaptation [37]. Moreover, to our knowledge, no data are present in the literature regarding the use of preoperative 3D images during robotic hepatectomies, and any result in terms of application and perioperative advantages in this field is pure speculation.

\subsection{Intra-Operative Robotic Ultrasound Application}

IOUS is nowadays an essential tool for hepatobiliary surgeons. Several series emphasize its utility in tumor identification, the recognition of its spatial relationship with intrahepatic structures, and, therefore, in guiding parenchymal resection [38]. Furthermore, IOUS is demonstrated to be able to modify preoperative strategy in up to a quarter of cases because of different vascular relationships or new nodules found during surgical exploration, despite the performance of a liver-specific MRI [39-41]. Similar results have been described in minimally invasive hepatectomies, with laparoscopic IOUS ensuring adequate perioperative and oncological safety compared to open liver surgery [42-45].

Originally, the Da Vinci platform did not include a dedicated ultrasound probe. To face this issue, a laparoscopic probe was inserted from the assistant trocar with the double inconvenience of difficult dexterity and the necessity of shifting from the robotic view to the external screen of the ultrasound because of the lack of an integrated system. Recently, a specific transducer was introduced to the robotic ecosystem with consequent better manageability, higher precision, and the creation of a multi-input environment. Surgeons can now easily control the probe, grabbing its dorsal fin with a forceps, and a highly flexible cable and a small transducer surface make the access to the posterior segments or to the inferior surface easier compared to the rigid laparoscopic counterpart [46,47]. Moreover, thanks to software such as TilePro, the operator can shift from the 3D camera view to the ultrasound directly from the console, or even create a split-view with both intraoperative and ultrasound images (Figure 4). Despite all the drawbacks related to the costs and a newborn technology, a few series regarding US-guided robotic liver resection have been published, and results seem promising in terms of surgical and oncological outcomes $[48,49]$. 




Figure 4. Robotic "split-view". Through a dedicated probe and a specific software, the surgeon can shift from to the endoscopic to the ultrasound view or create a split-view with both the images. In this figure, a 3D model was added intraoperatively at the same time to check the tumoral vascular relationship studied preoperatively.

Other interesting solutions in the field of the US-guider robotic liver surgery have been described in preclinical trials [50-52]. A Johns Hopkins group, in order to optimize even more the fusion between US and endoscopic views and thus create an unique multitasking environment, tested an open-source software through which images could be merged in different ways: (i) a split-screen display mode, with an endoscopic US side-by-side view; (ii) a picture-in-picture display mode, in which the US image was inserted in a corner of the camera view; and (iii) a "flashlight" mode, in which a 3D representation of the US image is overlaid in the surgical field on the same plane in which it is physically acquired by the transducer [50]. The two-dimensional (2D) images of the US remain, however, the biggest limitation of this method. Some authors created a 3D US reconstruction by assembling a series of 2D US images and, through a robotic platform, realized an ex vivo microwave liver ablation [51,52]. They concluded that this technique could eliminate error bias, reduce invasiveness (the number of insertions required) compared to manual needle insertion, and provide an accurate estimation of the micro-wave thermal field distribution.

\subsection{Indocyanine Green Fluorescence}

Indocyanine green (ICG) is a fluorescent dye with a rapid hepatic clearance largely used in hepato-biliary surgery thanks to its pharmacokinetics features $[53,54]$. After portal vein or intravenous injection [55], it allows the identification of anatomical liver vessels and biliary ducts by providing a rapid parenchymal mapping [54]. This enables anatomical resections with lower risks of vascular injuries or bile leaks. Moreover, it increases tumor detectability, helps differentiate hepatic lesions based on their vascular patterns, and allows the detection of additional superficial hepatic lesions [56-59].

Fluorescence software was incorporated into the Da Vinci system in 2010 and its application enhances robotic advantages in liver surgery from a different point of view. In fact, when a tumor-bearing portal vein injection is chosen-the so-called "negative staining" technique-this could be cumbersome in laparoscopic resections due to the impaired dexterity and lack of ergonomics, and, at the same time, the presence of a rigid linear transducer. The robotic system, through its delicate movements and endowrist instruments, ensures a fine and safe dissection of the hepatic pedicle, allowing it to reach the hilum and the portal bifurcation easier in the case of a direct portal injection [57-61]. 
Furthermore, through the dedicated probe, the transhepatic needle insertion could be also less demanding.

Another aspect to consider in ICG-guided resections is tumor clearance. Minimally invasive approaches - and robotic, in particular-lack a tactile feedback, and achieving a parenchymal free margin or performing an anatomical resection could be challenging. Furthermore, an IOUS exclusive evaluation could be insufficient because it is a userdependent procedure and presents a heterogeneous detection rate according to tumor size and location and parenchymal stiffness [62-64]. In this context, fluorescence is a precious tool in robotic surgery, with some authors reporting an enlargement of the resection area after ICG application, both in benign ad malignant lesions, in order to achieve a R0 resection [57,65-67], and a significantly higher rate of margin-free specimens when comparing robotic hepatectomies with and without ICG [67]. As in open surgery, even in robotic surgery, some series described the detection of newer superficial lesions that the dye injection missed before [57]. This high sensitivity found is, however, limited to the liver surface because of the low penetration of the dye under $8 \mathrm{~mm}$ of depth, thus requiring the use of other imaging tools such as IOUS. Although no long-term results have been published, these findings have a significant impact in terms of oncological outcomes.

ICG is a promising instrument of intraoperative navigation surgery, allowing rapid and easy identification of the resection plane without the inconveniences mentioned for other image-guided techniques. It can be used in combination with IOUS or AR as an additional aid rather than as a replacement [61] and with its features, it seems to fill some gaps found in robotic surgery, making tailored and oncological surgery less challenging.

\section{Future Prospective}

The application of the above-described technologies is nowadays limited in the robotic liver experience, mainly due to some technical limitations and to a relatively newborn and still debated approach [15]. AR, for example, is a time-consuming procedure, not only for the intraoperative installation, but also for preoperative planning and liver rendering [68]. In the context of an atypical or less demanding hepatic resection, which represent the first steps of a necessary learning curve, this time could appear exaggerated. Furthermore, AR in hepatic surgery has showed a delayed distribution compared to other surgical fields as neurosurgery, otolaryngology, orthopedics, and maxillofacial surgery [69-71]. This difference comes from anatomical obstacles, such as working with a deformable soft organ that is constantly moving during operation because of respiratory cycles as well as pneumoperitoneum creation [72]. Although some strategies have been described in this context $[23,73,74]$, these features make the development of AR more complex, and new software are needed for shortening modeling creation and improving the accuracy of manual, semiautomatic, and automatic images overlapping.

All the imaging techniques described must be seen, however, as a part of a puzzle rather than an independent solution towards a guided surgery; an example comes from registration accuracy in AR. IOUS and ICG have been proposed to improve overlapping quality through fluorescent markers and 3D ultrasounds used for intraoperative landmarks $[75,76]$. In this scenario, the robotic platform fits perfectly by creating a unique merged environment with the possibility of using and visualizing preoperative reconstruction and intraoperative images simultaneously within the operative field (Figure 4).

Another potential benefit of image-guided technology is minimally invasive training. In laparoscopy, telementoring based on AR seems to speed up simple skills acquisition such as suturing [77] or even reduce the learning curve in more complex procedures such as cholecystectomy [78]. Similar applications in robotic training are lacking, with only a few experiences described [79]. Hepato-biliary surgery lacks standards of training and learning curves in robotic procedures [80], but recently, an expert panel of HPB surgeons agreed that a correct training path in hepatobiliary procedures needs different steps, starting from basic robotic skills before performing a liver resection [81]. In this context, AR could be a 
useful tool to support less-experienced surgeons performing simple procedures and lower their learning curve.

\section{Conclusions}

The application of pre- and intra-operative imaging modalities in guiding hepatic surgery presents promising results, and the robotic ecosystem can facilitate their use and magnify their benefits. Potential advantages include reduced morbidity and improvements in oncological outcomes. However, some limitations are still present, related to limited robotic diffusion and still insufficient technological development, and most of the data in the literature come from preclinical studies or small series.

Author Contributions: Conceptualization, F.G., E.F. and P.P.; methodology, F.G.; validation, F.G., E.F. and P.P.; formal analysis, F.G. and P.P.; investigation, F.G.; data curation, F.G. and P.P.; writing-original draft preparation, F.G.; writing-review and editing, E.F., Z.C., P.M. and P.P.; visualization, F.G. and P.P.; supervision, E.F. and P.P.; project administration, F.G. All authors have read and agreed to the published version of the manuscript.

Funding: This research received no external funding.

Acknowledgments: This work was supported by French state funds managed within the "Plan Investissements d'Avenir" and by the ANR (reference ANR-10-IAHU-02).

Conflicts of Interest: The authors declare no conflict of interest.

\section{References}

1. Ciria, R.; Cherqui, D.; Geller, D.A.; Briceno, J.; Wakabayashi, G. Comparative Short-term Benefits of Laparoscopic Liver Resection. Ann. Surg. 2016, 263, 761-777. [CrossRef]

2. Wakabayashi, G.; Cherqui, D.; Geller, D.A.; Buell, J.F.; Kaneko, H.; Han, H.S.; Asbun, H.; O'rourke, N.; Tanabe, M.; Koffron, A.J.; et al. Recommendations for laparoscopic liver resection: A report from the second international consensus conference held in Morioka. Ann. Surg. 2015, 261, 619-629. [CrossRef] [PubMed]

3. Kasai, M.; Cipriani, F.; Gayet, B.; Aldrighetti, L.; Ratti, F.; Sarmiento, J.M.; Scatton, O.; Kim, K.-H.; Dagher, I.; Topal, B.; et al. Laparoscopic versus open major hepatectomy: A systematic review and meta-analysis of individual patient data. Surgery 2018, 163, 985-995. [CrossRef] [PubMed]

4. Machairas, N.; Kostakis, I.D.; Schizas, D.; Kykalos, S.; Nikiteas, N.; Sotiropoulos, G.C. Meta-analysis of laparoscopic versus open liver resection for intrahepatic cholangiocarcinoma. Updates Surg. 2020, 73, 59-68. [CrossRef] [PubMed]

5. Guerrini, G.P.; Esposito, G.; Tarantino, G.; Serra, V.; Olivieri, T.; Catellani, B.; Assirati, G.; Guidetti, C.; Ballarin, R.; Magistri, P.; et al. Laparoscopic versus open liver resection for intrahepatic cholangiocarcinoma: The first meta-analysis. Langenbeck's Arch. Surg. 2020, 405, 265-275. [CrossRef]

6. Sotiropoulos, G.C.; Prodromidou, A.; Kostakis, I.D.; Machairas, N. Meta-analysis of laparoscopic vs open liver resection for hepatocellular carcinoma. Updates Surg. 2017, 69, 291-311. [CrossRef]

7. Syn, N.L.; Kabir, T.; Koh, Y.X.; Tan, H.L.; Wang, L.Z.; Chin, B.Z.; Wee, I.; Teo, J.Y.; Tai, B.C.; Goh, B.K.P. Survival Advantage of Laparoscopic Versus Open Resection For Colorectal Liver Metastases. Ann. Surg. 2019, 272, 253-265. [CrossRef]

8. Schmelzle, M.; Krenzien, F.; Schöning, W.; Pratschke, J. Laparoscopic liver resection: Indications, limitations, and economic aspects. Langenbeck's Arch. Surg. 2020, 405, 725-735. [CrossRef]

9. Tsung, A.; Geller, D.A.; Sukato, D.C.; Sabbaghian, S.; Tohme, S.; Steel, J.; Marsh, W.; Reddy, S.K.; Bartlett, D.L. Robotic Versus Laparoscopic Hepatectomy. Ann. Surg. 2014, 259, 549-555. [CrossRef] [PubMed]

10. Gavriilidis, P.; Roberts, K.J.; Aldrighetti, L.; Sutcliffe, R.P. A comparison between robotic, laparoscopic and open hepatectomy: A systematic review and network meta-analysis. Eur. J. Surg. Oncol. 2020, 46, 1214-1224. [CrossRef]

11. Zhao, Z.; Yin, Z.; Li, M.; Jiang, N.; Liu, R. State of the art in robotic liver surgery: A meta-analysis. Updates Surg. 2020, 73, 977-987. [CrossRef] [PubMed]

12. Zhang, L.; Yuan, Q.; Xu, Y.; Wang, W. Comparative clinical outcomes of robot-assisted liver resection versus laparoscopic liver resection: A meta-analysis. PLoS ONE 2020, 15, e240593. [CrossRef]

13. Machairas, N.; Papaconstantinou, D.; Tsilimigras, D.I.; Moris, D.; Prodromidou, A.; Paspala, A.; Spartalis, E.; Kostakis, I.D. Comparison between robotic and open liver resection: A systematic review and meta-analysis of short-term outcomes. Updates Surg. 2019, 71, 39-48. [CrossRef]

14. Tsilimigras, D.I.; Moris, D.; Vagios, S.; Merath, K.; Pawlik, T.M. Safety and oncologic outcomes of robotic liver resections: A systematic review. J. Surg. Oncol. 2018, 117, 1517-1530. [CrossRef]

15. Liu, R.; Wakabayashi, G.; Kim, H.-J.; Choi, G.-H.; Yiengpruksawan, A.; Fong, Y.; He, J.; Boggi, U.; Troisi, R.I.; Efanov, M.; et al. International consensus statement on robotic hepatectomy surgery in 2018. World J. Gastroenterol. 2019, 25, 1432-1444. [CrossRef] [PubMed] 
16. Giménez, M.; Gallix, B.; Costamagna, G.; Vauthey, J.-N.; Moche, M.; Wakabayashi, G.; Bale, R.; Swanström, L.; Futterer, J.; Geller, D.; et al. Definitions of Computer-Assisted Surgery and Intervention, Image-Guided Surgery and Intervention, Hybrid Operating Room, and Guidance Systems. Ann. Surg. Open 2020, 1, e21. [CrossRef] [PubMed]

17. Okuda, Y.; Taura, K.; Seo, S.; Yasuchika, K.; Nitta, T.; Ogawa, K.; Hatano, E.; Uemoto, S. Usefulness of operative planning based on 3-dimensional CT cholangiography for biliary malignancies. Surgery 2015, 158, 1261-1271. [CrossRef] [PubMed]

18. Fang, C.-H.; Tao, H.-S.; Yang, J.; Fang, Z.-S.; Cai, W.; Liu, J.; Fan, Y.-F. Impact of Three-Dimensional Reconstruction Technique in the Operation Planning of Centrally Located Hepatocellular Carcinoma. J. Am. Coll. Surg. 2014, 220, 28-37. [CrossRef]

19. Hallet, J.; Soler, L.; Diana, M.; Mutter, D.; Baumert, T.F.; Habersetzer, F.; Marescaux, J.; Pessaux, P. Trans-Thoracic Minimally Invasive Liver Resection Guided by Augmented Reality. J. Am. Coll. Surg. 2015, 220, e55-e60. [CrossRef] [PubMed]

20. Phutane, P.; Buc, E.; Poirot, K.; Ozgur, E.; Pezet, D.; Bartoli, A.; Le Roy, B. Preliminary trial of augmented reality performed on a laparoscopic left hepatectomy. Surg. Endosc. 2017, 32, 514-515. [CrossRef]

21. Mise, Y.; Hasegawa, K.; Satou, S.; Shindoh, J.; Miki, K.; Akamatsu, N.; Arita, J.; Kaneko, J.; Sakamoto, Y.; Kokudo, N. How Has Virtual Hepatectomy Changed the Practice of Liver Surgery? Ann. Surg. 2018, 268, 127-133. [CrossRef]

22. Buchs, N.C.; Volonte, F.; Pugin, F.; Toso, C.; Fusaglia, M.; Gavaghan, K.; Majno, P.E.; Peterhans, M.; Weber, S.; Morel, P. Augmented environments for the targeting of hepatic lesions during image-guided robotic liver surgery. J. Surg. Res. 2013, 184, 825-831. [CrossRef] [PubMed]

23. Ntourakis, D.; Memeo, R.; Soler, L.; Marescaux, J.; Mutter, D.; Pessaux, P. Augmented Reality Guidance for the Resection of Missing Colorectal Liver Metastases: An Initial Experience. World J. Surg. 2015, 40, 419-426. [CrossRef]

24. Kingham, T.P.; Pak, L.M.; Simpson, A.L.; Leung, U.; Doussot, A.; D’Angelica, M.I.; DeMatteo, R.P.; Allen, P.J.; Jarnagin, W.R. 3D image guidance assisted identification of colorectal cancer liver metastases not seen on intraoperative ultrasound: Results from a prospective trial. HPB 2017, 20, 260-267. [CrossRef]

25. Banz, V.M.; Müller, P.C.; Tinguely, P.; Inderbitzin, D.; Ribes, D.; Peterhans, M.; Candinas, D.; Weber, S. Intraoperative imageguided navigation system: Development and applicability in 65 patients undergoing liver surgery. Langenbeck's Arch. Surg. 2016, 401, 495-502. [CrossRef] [PubMed]

26. Diana, M.; Soler, L.; Agnus, V.; D’Urso, A.; Vix, M.; Dallemagne, B.; Faucher, V.; Roy, C.; Mutter, D.; Marescaux, J.; et al. Prospective Evaluation of Precision Multimodal Gallbladder Surgery Navigation. Ann. Surg. 2017, 266, 890-897. [CrossRef] [PubMed]

27. Otsuka, Y.; Kaneko, H.; Cleary, S.P.; Buell, J.F.; Cai, X.; Wakabayashi, G. What is the best technique in parenchymal transection in laparoscopic liver resection? Comprehensive review for the clinical question on the 2nd International Consensus Conference on Laparoscopic Liver Resection. J. Hepato-Biliary-Pancreat. Sci. 2015, 22, 363-370. [CrossRef]

28. Pessaux, P.; Diana, M.; Soler, L.; Piardi, T.; Mutter, D.; Marescaux, J. Towards cybernetic surgery: Robotic and augmented reality-assisted liver segmentectomy. Langenbeck's Arch. Surg. 2014, 400, 381-385. [CrossRef] [PubMed]

29. Hao, W.; Binbin, J.; Wei, Y.; Kun, Y. Can Radiofrequency Ablation Replace Liver Resection for Solitary Colorectal Liver Metastasis? A Systemic Review and Meta-Analysis. Front. Oncol. 2020, 10, 561669. [CrossRef]

30. Wen, R.; Chui, C.-K.; Ong, S.-H.; Lim, K.-B.; Chang, S.K.-Y. Projection-based visual guidance for robot-aided RF needle insertion. Int. J. Comput. Assist. Radiol. Surg. 2013, 8, 1015-1025. [CrossRef] [PubMed]

31. Wen, R.; Tay, W.-L.; Nguyen, B.P.; Chng, C.-B.; Chui, C.-K. Hand gesture guided robot-assisted surgery based on a direct augmented reality interface. Comput. Methods Programs Biomed. 2014, 116, 68-80. [CrossRef] [PubMed]

32. Woo, Y.; Choi, G.H.; Min, B.S.; Hyung, W.J. Novel application of simultaneous multi-image display during complex robotic abdominal procedures. BMC Surg. 2014, 14, 13. [CrossRef]

33. Marescaux, J.; Clément, J.-M.; Tassetti, V.; Koehl, C.; Cotin, S.; Russier, Y.; Mutter, D.; Delingette, H.; Ayache, N. Virtual Reality Applied to Hepatic Surgery Simulation: The Next Revolution. Ann. Surg. 1998, 228, 627-634. [CrossRef] [PubMed]

34. Palomar, R.; Cheikh, F.A.; Edwin, B.; Fretland, Å.; Beghdadi, A.; Elle, O.J. A novel method for planning liver resections using deformable Bézier surfaces and distance maps. Comput. Methods Programs Biomed. 2017, 144, 135-145. [CrossRef]

35. Xiang, N.; Fang, C.; Fan, Y.; Yang, J.; Zeng, N.; Liu, J.; Zhu, W. Application of liver three-dimensional printing in hepatectomy for complex massive hepatocarcinoma with rare variations of portal vein: Preliminary experience. Int. J. Clin. Exp. Med. 2015, 8, 18873-18878. [PubMed]

36. Li, P.; Wang, M.; Yang, Y.; Liu, H.; Pan, Z.; Jiang, B.; Lau, W.Y.; Huang, G.; Zhou, W. Preoperative three-dimensional versus two-dimensional evaluation in assessment of patients undergoing major liver resection for hepatocellular carcinoma: A propensity score matching study. Ann. Transl. Med. 2020, 8, 182. [CrossRef]

37. Fang, C.; An, J.; Bruno, A.; Cai, X.; Fan, J.; Fujimoto, J.; Golfieri, R.; Hao, X.; Jiang, H.; Jiao, L.R.; et al. Consensus recommendations of three-dimensional visualization for diagnosis and management of liver diseases. Hepatol. Int. 2020, 14, 437-453. [CrossRef]

38. Araki, K.; Conrad, C.; Ogiso, S.; Kuwano, H.; Gayet, B. Intraoperative Ultrasonography of Laparoscopic Hepatectomy: Key Technique for Safe Liver Transection. J. Am. Coll. Surg. 2013, 218, e37-e41. [CrossRef] [PubMed]

39. Ferrero, A.; Langella, S.; Giuliante, F.; Viganò, L.; Vellone, M.; Zimmitti, G.; Ardito, F.; Nuzzo, G.; Capussotti, L. Intraoperative Liver Ultrasound Still Affects Surgical Strategy for Patients with Colorectal Metastases in the Modern Era. World J. Surg. 2013, 37, 2655-2663. [CrossRef]

40. Langella, S.; Ardito, F.; Russolillo, N.; Panettieri, E.; Perotti, S.; Mele, C.; Giuliante, F.; Ferrero, A. Intraoperative Ultrasound Staging for Colorectal Liver Metastases in the Era of Liver-Specific Magnetic Resonance Imaging: Is It Still Worthwhile? J. Oncol. 2019, 2019, 1369274. [CrossRef] [PubMed] 
41. D’Hondt, M.; Vandenbroucke-Menu, F.; Préville-Ratelle, S.; Turcotte, S.; Chagnon, M.; Plasse, M.; Létourneau, R.; Dagenais, M.; Roy, A.; Lapointe, R. Is intra-operative ultrasound still useful for the detection of a hepatic tumour in the era of modern pre-operative imaging? HРВ 2011, 13, 665-669. [CrossRef]

42. Viganò, L.; Ferrero, A.; Amisano, M.; Russolillo, N.; Capussotti, L. Comparison of laparoscopic and open intraoperative ultrasonography for staging liver tumours. BJS 2013, 100, 535-542. [CrossRef] [PubMed]

43. Langella, S.; Russolillo, N.; D’Eletto, M.; Forchino, F.; Tesoriere, R.L.; Ferrero, A. Oncological safety of ultrasound-guided laparoscopic liver resection for colorectal metastases: A case-control study. Updates Surg. 2015, 67, 147-155. [CrossRef] [PubMed]

44. Ferrero, A.; Russolillo, N.; Langella, S.; Forchino, F.; Stasi, M.; Fazio, F.; Tesoriere, R.L. Ultrasound liver map technique for laparoscopic liver resections: Perioperative outcomes are not impaired by technical complexity. Updates Surg. 2019, 71, 49-56. [CrossRef]

45. Russolillo, N.; Borello, A.; Langella, S.; Casella, M.; Tesoriere, R.L.; Ferrero, A. Comparison of laparoscopic ultrasound and liver-specific magnetic resonance imaging for staging colorectal liver metastases. Surg. Endosc. 2020, 35, 3547-3553. [CrossRef]

46. Cho, J.Y. Outcomes of Laparoscopic Liver Resection for Lesions Located in the Right Side of the Liver. Arch. Surg. 2009, 144, 25-29. [CrossRef]

47. Casciola, L.; Patriti, A.; Ceccarelli, G.; Bartoli, A.; Ceribelli, C.; Spaziani, A. Robot-assisted parenchymal-sparing liver surgery including lesions located in the posterosuperior segments. Surg. Endosc. 2011, 25, 3815-3824. [CrossRef]

48. Pesi, B.; Moraldi, L.; Guerra, F.; Tofani, F.; Nerini, A.; Annecchiarico, M.; Coratti, A. Surgical and oncological outcomes after ultrasound-guided robotic liver resections for malignant tumor. Analysis of a prospective database. Int. J. Med. Robot. Comput. Assist. Surg. 2019, 15, e2002. [CrossRef] [PubMed]

49. Guerra, F.; Guadagni, S.; Pesi, B.; Furbetta, N.; Di Franco, G.; Palmeri, M.; Annecchiarico, M.; Eugeni, E.; Coratti, A.; Patriti, A.; et al. Outcomes of robotic liver resections for colorectal liver metastases. A multi-institutional analysis of minimally invasive ultrasound-guided robotic surgery. Surg. Oncol. 2018, 28, 14-18. [CrossRef]

50. Schneider, C.M.; Peng, P.D.; Taylor, R.H.; Dachs, G.W.; Hasser, C.J.; DiMaio, S.P.; Choti, M.A. Robot-assisted laparoscopic ultrasonography for hepatic surgery. Surgery 2012, 151, 756-762. [CrossRef] [PubMed]

51. Boctor, E.M.; Choti, M.A.; Burdette, E.C.; Webster, R.J., III. Three-dimensional ultrasound-guided robotic needle placement: An experimental evaluation. Int. J. Med. Robot. Comput. Assist. Surg. 2008, 4, 180-191. [CrossRef]

52. Xu, J.; Jia, Z.-Z.; Song, Z.-J.; Yang, X.-D.; Chen, K.; Liang, P. Three-dimensional ultrasound image-guided robotic system for accurate microwave coagulation of malignant liver tumours. Int. J. Med. Robot. Comput. Assist. Surg. 2010, 6, 256-268. [CrossRef] [PubMed]

53. Majlesara, A.; Golriz, M.; Hafezi, M.; Saffari, A.; Stenau, E.; Maier-Hein, L.; Müller-Stich, B.P.; Mehrabi, A. Indocyanine green fluorescence imaging in hepatobiliary surgery. Photodiagnosis Photodyn. Ther. 2017, 17, 208-215. [CrossRef] [PubMed]

54. Reinhart, M.B.; Huntington, C.R.; Blair, L.J.; Heniford, B.T.; Augenstein, V.A. Indocyanine Green. Surg. Innov. 2015, 23, 166-175. [CrossRef] [PubMed]

55. Daskalaki, D.; Aguilera, F.; Patton, K.; Giulianotti, P.C. Fluorescence in robotic surgery. J. Surg. Oncol. 2015, 112, 250-256. [CrossRef]

56. Handgraaf, H.; Boogerd, L.; Höppener, D.; Peloso, A.; Mulder, B.S.; Hoogstins, C.; Hartgrink, H.; van de Velde, C.; Mieog, J.; Swijnenburg, R.; et al. Long-term follow-up after near-infrared fluorescence-guided resection of colorectal liver metastases: A retrospective multicenter analysis. Eur. J. Surg. Oncol. 2017, 43, 1463-1471. [CrossRef] [PubMed]

57. Marino, M.V.; Podda, M.; Fernandez, C.C.; Ruiz, M.G.; Fleitas, M.G. The application of indocyanine green-fluorescence imaging during robotic-assisted liver resection for malignant tumors: A single-arm feasibility cohort study. HPB 2020, $22,422-431$. [CrossRef]

58. Van Der Vorst, J.R.; Schaafsma, B.E.; Hutteman, M.; Msc, F.P.R.V.; Liefers, G.-J.; Hartgrink, H.H.; Smit, V.T.H.B.M.; Löwik, C.W.G.M.; Van De Velde, C.J.H.; Frangioni, J.V.; et al. Near-infrared fluorescence-guided resection of colorectal liver metastases. Cancer 2013, 119, 3411-3418. [CrossRef]

59. Hoekstra, L.T.; de Graaf, W.; Nibourg, G.A.A.; Heger, M.; Bennink, R.J.; Stieger, B.; van Gulik, T.M. Physiological and Biochemical Basis of Clinical Liver Function Tests. Ann. Surg. 2013, 257, 27-36. [CrossRef]

60. Cheung, T.T.; Ma, K.W.; She, W.H.; Dai, W.C.; Tsang, S.H.Y.; Chan, A.C.Y.; Chok, K.S.H.; Lo, C.M. Pure laparoscopic hepatectomy with augmented reality-assisted indocyanine green fluorescence versus open hepatectomy for hepatocellular carcinoma with liver cirrhosis: A propensity analysis at a single center. Asian J. Endosc. Surg. 2018, 11, 104-111. [CrossRef]

61. Chiow, A.K.H.; Rho, S.Y.; Wee, I.J.; Lee, L.S.; Choi, G.H. Robotic ICG guided anatomical liver resection in a multi-centre cohort: An evolution from "positive staining" into "negative staining" method. HPB 2020, 23, 475-482. [CrossRef] [PubMed]

62. Ishizawa, T.; Fukushima, N.; Shibahara, J.; Masuda, K.; Tamura, S.; Aoki, T.; Hasegawa, K.; Beck, Y.; Fukayama, M.; Kokudo, N. Real-time identification of liver cancers by using indocyanine green fluorescent imaging. Cancer 2009, 115, 2491-2504. [CrossRef] [PubMed]

63. Boogerd, L.S.F.; Handgraaf, H.; Lam, H.-D.; Huurman, V.A.L.; Sarasqueta, A.F.; Frangioni, J.V.; Van De Velde, C.J.H.; Braat, A.E.; Vahrmeijer, A.L. Laparoscopic detection and resection of occult liver tumors of multiple cancer types using real-time near-infrared fluorescence guidance. Surg. Endosc. 2016, 31, 952-961. [CrossRef] [PubMed] 
64. Peloso, A.; Franchi, E.; Canepa, M.C.; Barbieri, L.; Briani, L.; Ferrario, J.; Bianco, C.; Quaretti, P.; Brugnatelli, S.; Dionigi, P.; et al. Combined use of intraoperative ultrasound and indocyanine green fluorescence imaging to detect liver metastases from colorectal cancer. HPB 2013, 15, 928-934. [CrossRef]

65. Li, C.-G.; Zhou, Z.-P.; Tan, X.-L.; Wang, Z.-Z.; Liu, Q.; Zhao, Z.-M. Robotic resection of liver focal nodal hyperplasia guided by indocyanine green fluorescence imaging: A preliminary analysis of 23 cases. World J. Gastrointest. Oncol. 2020, 12, 1407-1415. [CrossRef]

66. Mehdorn, A.-S.; Beckmann, J.; Braun, F.; Becker, T.; Egberts, J.-H. Usability of Indocyanine Green in Robot-Assisted Hepatic Surgery. J. Clin. Med. 2021, 10, 456. [CrossRef] [PubMed]

67. Marino, M.V.; Di Saverio, S.; Podda, M.; Ruiz, M.G.; Fleitas, M.G. The Application of Indocyanine Green Fluorescence Imaging During Robotic Liver Resection: A Case-Matched Study. World J. Surg. 2019, 43, 2595-2606. [CrossRef]

68. Okamoto, T.; Onda, S.; Yanaga, K.; Suzuki, N.; Hattori, A. Clinical application of navigation surgery using augmented reality in the abdominal field. Surg. Today 2014, 45, 397-406. [CrossRef]

69. Meola, A.; Cutolo, F.; Carbone, M.; Cagnazzo, F.; Ferrari, M.; Ferrari, V. Augmented reality in neurosurgery: A systematic review. Neurosurg. Rev. 2016, 40, 537-548. [CrossRef]

70. Jud, L.; Fotouhi, J.; Andronic, O.; Aichmair, A.; Osgood, G.; Navab, N.; Farshad, M. Applicability of augmented reality in orthopedic surgery-A systematic review. BMC Musculoskelet. Disord. 2020, 21, 103. [CrossRef]

71. Ayoub, A.; Pulijala, Y. The application of virtual reality and augmented reality in Oral \& Maxillofacial Surgery. BMC Oral Health 2019, 19, 238. [CrossRef]

72. Teatini, A.; de Frutos, J.P.; Eigl, B.; Pelanis, E.; Aghayan, D.L.; Lai, M.; Kumar, R.P.; Palomar, R.; Edwin, B.; Elle, O.J. Influence of sampling accuracy on augmented reality for laparoscopic image-guided surgery. Minim. Invasive Ther. Allied Technol. 2020, 30, 229-238. [CrossRef]

73. Kenngott, H.G.; Wagner, M.; Gondan, M.; Nickel, F.; Nolden, M.; Fetzer, A.; Weitz, J.; Fischer, L.; Speidel, S.; Meinzer, H.-P.; et al. Real-time image guidance in laparoscopic liver surgery: First clinical experience with a guidance system based on intraoperative CT imaging. Surg. Endosc. 2013, 28, 933-940. [CrossRef]

74. Luo, H.; Yin, D.; Zhang, S.; Xiao, D.; He, B.; Meng, F.; Zhang, Y.; Cai, W.; He, S.; Zhang, W.; et al. Augmented reality navigation for liver resection with a stereoscopic laparoscope. Comput. Methods Programs Biomed. 2019, 187, 105099. [CrossRef]

75. Nam, W.H.; Kang, D.-G.; Lee, D.; Lee, J.Y.; Ra, J.B. Automatic registration between 3D intra-operative ultrasound and pre-operative CT images of the liver based on robust edge matching. Phys. Med. Biol. 2011, 57, 69-91. [CrossRef]

76. Kong, S.-H.; Haouchine, N.; Soares, R.; Klymchenko, A.S.; Andreiuk, B.; Marques, B.; Shabat, G.; Piechaud, T.; Diana, M.; Cotin, S.; et al. Robust augmented reality registration method for localization of solid organs' tumors using CT-derived virtual biomechanical model and fluorescent fiducials. Surg. Endosc. 2016, 31, 2863-2871. [CrossRef]

77. Vera, A.M.; Russo, M.; Mohsin, A.; Tsuda, S. Augmented reality telementoring (ART) platform: A randomized controlled trial to assess the efficacy of a new surgical education technology. Surg. Endosc. 2014, 28, 3467-3472. [CrossRef]

78. Kowalewski, K.-F.; Garrow, C.; Proctor, T.; Preukschas, A.A.; Friedrich, M.; Müller, P.C.; Kenngott, H.G.; Fischer, L.; MüllerStich, B.P.; Nickel, F. LapTrain: Multi-modality training curriculum for laparoscopic cholecystectomy-results of a randomized controlled trial. Surg. Endosc. 2018, 32, 3830-3838. [CrossRef]

79. Lee, J.H.; Tanaka, E.; Woo, Y.; Ali, G.; Son, T.; Kim, H.; Hyung, W.J. Advanced real-time multi-display educational system (ARMES): An innovative real-time audiovisual mentoring tool for complex robotic surgery. J. Surg. Oncol. 2017, 116, 894-897. [CrossRef]

80. Lai, E.C.; Tang, C.N. Training robotic hepatectomy: The Hong Kong experience and perspective. Hepatobiliary Surg. Nutr. 2017, 6, 222-229. [CrossRef]

81. Fong, Y.; Buell, J.F.; Collins, J.; Martinie, J.; Bruns, C.; Tsung, A.; Clavien, P.-A.; Nachmany, I.; Edwin, B.; Pratschke, J.; et al. Applying the Delphi process for development of a hepatopancreaticobiliary robotic surgery training curriculum. Surg. Endosc. 2020, 34, 4233-4244. [CrossRef] 